\title{
Alkaloid Profiling of Hippeastrum Cultivars by GC-MS, Isolation of Amaryllidaceae Alkaloids and Evaluation of Their Cytotoxicity
}

\author{
Latifah Al Shammari $\oplus^{1}$, Abdullah Al Mamun $\oplus^{1}$, Darja Koutová $\oplus^{2}$, \\ Martina Majorošová ${ }^{2}$, Daniela Hulcová ${ }^{1,3}$, Marcela Šafratová ${ }^{3}$, \\ Kateřina Breiterová ${ }^{1}$, Jana Mař́ková ${ }^{4}$, Radim Havelek ${ }^{2}$ and \\ Lucie Cahlíková 1,*
}

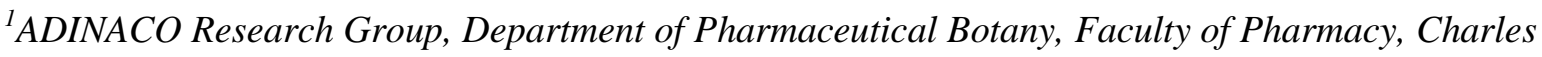 \\ University, Heyrovskeho 1203, 50005 Hradec Kralove, Czech Republic \\ ${ }^{2}$ Department of Medical Biochemistry, Faculty of Medicine in Hradec Kralove, Charles University, \\ Simkova 870, Hradec Kralove 500 03, Czech Republic \\ ${ }^{3}$ Department of Pharmacognosy, Faculty of Pharmacy, Charles University, Heyrovskeho 1203, 50005 \\ Hradec Kralove, Czech Republic \\ ${ }^{4}$ Department of Organic and Bioorganic Chemistry, Faculty of Pharmacy, Charles University, \\ Heyrovskeho 1203, 50005 Hradec Kralove, Czech Republic
}

(Received June 17, 2019; Revised August 28, 2019; Accepted August 29, 2019)

\begin{abstract}
Different species, hybrids and varieties of the genus Hippeastrum (Amaryllidaceae) are planted for ornamental purposes and at the same time they represent a rich source of interesting secondary metabolites called Amaryllidaceae alkaloids. These compounds display a wide spectrum of biological activities. In the current study, six Hippeastrum taxa were evaluated for their alkaloid profile by GC-MS. Using preparative TLC, five alkaloids were isolated in pure form, and three of them evaluated for cytotoxic and antiproliferative potencies on a panel of human cancer cells of different histotype (Jurkat, MOLT-4, A549, HT-29, PANC-1, A2780, HeLa, MCF-7 and SAOS-2). In parallel, normal MRC-5 human fibroblasts were employed to determine the compounds' overall toxicity against non-cancer cells. The most intriguing cytotoxic profile was demonstrated by montanine (1) with $\mathrm{IC}_{50}$ values between $1.04-1.99 \mu \mathrm{M}$.
\end{abstract}

Keywords: Amaryllidaceae; Hippeastrum; alkaloids; montanine; cytotoxicity. ㄷ 2019 ACG Publications. All rights reserved.

\section{Plant Source}

In the course of phytochemical studies of Amaryllidaceae plants we analysed different Hippeastrum cultivars. The fresh bulbs of all Hippeastrum taxa (between $150 \mathrm{~g}-250 \mathrm{~g}$ ) were obtained from the herbal dealer Lukon Glads (Sadská, Czech Republic). The botanical identification was performed by Prof. L. Opletal, CSc. Voucher specimens are deposited in the herbarium of the Faculty of

\footnotetext{
*Corresponding author: E-Mail: cahlikova@ faf.cuni.cz 
Pharmacy in Hradec Králové under the following numbers: Hippeastrum cv. Pretty Nymph CUFPH16130/AL-569, H. cv. Artic Nymph CUFPH-16130/AL-574, H. cv. Daphne CUFPH-16130/AL-563, $H$. cv. Double King CUFPH-16130/AL-567, H. cv. Ferrari CUFPH-16130/AL-562, and H. cv. Spartacus CUFPH-16130/AL-570.

\section{Previous Studies}

Plants of the genus Hippeastrum, commonly called amaryllis, and Amaryllis belladonna, commonly called belladonna lily or naked lady, are similar in appearance except that $A$. belladonna has a solid flower stem while Hippeastrum has a hollow one [1]. Plants known as "amaryllis", "Dutch amaryllis", and "giant amaryllis" belong to the genus Hippeastrum, and those grown today are mostly hybrids of several species from South America and South Africa. Hippeastrum species have been traditionally used to cure piles, tumors and various inflammatory disorders [2].

The antitumor properties of the Amaryllidaceae alkaloids, such as lycorine, haemanthamine, and pancratistatine, are well known [3]. Lycorine and haemanthamine are easily isolated from natural sources and displayed significant in vitro cytotoxic activity against several different types of cancer cell lines including MOLT-4, Hep-G2, HeLa, MCF-7, CEM, K562, A549, Caco-2, and HT-29 [4,5].

The Amaryllidaceous cultivars have advantages for commercial alkaloid production since they are available in large quantities. To our knowledge, no studies have been carried out until now on the alkaloidal profile of a collection of Hippeastrum cultivars. In the current study, six Hippeastrum horticultural cultivars were evaluated for their alkaloid profile by GC-MS. Furthermore, five alkaloids were isolated in pure form from alkaloidal extracts and three of them were tested for their cytotoxic activity. The cytotoxicity of the isolated compounds has been studied on a panel of ten cancerous and noncancerous cell lines.

\section{Present Study}

In the bulb extracts of the studied six ornamental varieties of Hippeastrum cultivars, 20 compounds with typical mass spectra of Amaryllidaceae alkaloids were detected. Eighteen of them were identified based on their mass spectra, retention times and retention indexes and belong to the crinine, haemanthamine, galanthamine, homolycorine, lycorine, montanine, and tazettine structural types of Amaryllidaceae alkaloids. The alkaloids marked as A1, A2 and A3 displayed mass spectra typical for Amaryllidaceae alkaloids, however left unidentified. Considering their low concentrations ( $<5 \%$ of TIC), their isolation and structural elucidation could be problematic. From the mass spectrum of alkaloid A2, some structural aspects can be concluded. The fragmentation pattern, especially the presence of an intense peak at $\mathrm{m} / \mathrm{z} 109$ such as in masonine and homolycorine [6], indicates the homolycorine structural-type of Amaryllidaceae alkaloids. Other fragments of the mass spectrum displayed only weak intensities, and are not valuable for exact identification of detected alkaloid. The relative proportion of each alkaloid was determined as a percentage of the total ion current (TIC). The peak areas reflect the ability of each compound to be ionized and thus the data given in Table 1 are semiquantitative. Nevertheless, they can be used for comparison between samples. Furthermore, five Amaryllidaceae alkaloids from different Hippeastrum cultivars have been isolated by preparative TLC in pure form.

Based on the obtained GC-MS results it can be concluded that cultivars of Hippeastrum are a rich source of different biologically active Amaryllidaceae alkaloids (Table 1). Lycorine, the most abundant Amaryllidaceae alkaloid, has been identified in all the studied cultivars, with the highest concentration being detected in Hippeastrum cv. Daphne (56\% of TIC). In fresh bulbs, galanthamine, the most well known Amaryllidaceae alkaloid, was detected, but only in some cultivars, and mostly in trace concentration. In the alkaloidal extract of $H$. cv. Pretty Nymph, two alkaloids of the homolycorine structural type have been identified as major components, namely homolycorine (40\% of TIC) and hippeastrine ( $22 \%$ of TIC).

Using preparative TLC, five Amaryllidaceae alkaloids (Figure 1) have been isolated in pure form from various Hippeastrum cultivars. The compounds were identified by MS, 1D and 2D NMR spectroscopic analyses and by comparison of the obtained data with the literature as montanine (1), vittatine (2), 11-hydroxyvittatine (3), lycorine (4) and hippeastrine (5). 
<smiles>CO[C@H]1C=C2[C@@H](CO)N3Cc4cc5c(cc4[C@@H](C[C@@H]23)[C@@H]1O)OCO5</smiles>

(1)<smiles>O[C@H]1C=CC23CC[C@@H](C1)CN(C2)C3</smiles>

(2)<smiles>OC1CC[C@]23C=C[C@@H](O)CC2N(Cc2cc4c(cc23)OCO4)C1</smiles>

(3)<smiles></smiles>

(4)<smiles>CN1CCC2=C[C@H](O)[C@H]3OC(=O)c4cc5c(cc4[C@]3(C)C21)OCO5</smiles><smiles>CO[C@H]1C=C2Cc3cc4c(cc3CN2[C@@H]2C[C@H]1C[C@H]2OC)OCO4</smiles>

(6)

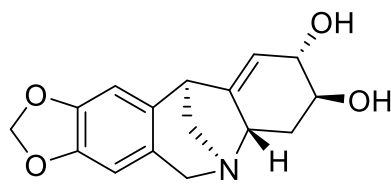

(7)

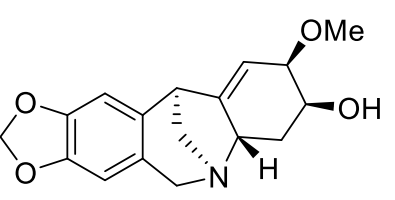

(8)

Figure 1. Structures of isolated Amaryllidaceae alkaloids from Hippeastrum cultivars, and structures of discussed Amaryllidaceae alkaloids of montanine-structural type

Table 1. Composition of the alkaloidal extracts of six Hippeastrum cultivars analyzed by GC-MS

\begin{tabular}{|c|c|c|c|c|c|c|c|c|c|}
\hline Alkaloid & RI & $\begin{array}{c}\text { Liter. } \\
\text { values } \\
\text { of RI }\end{array}$ & 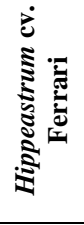 & 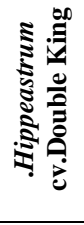 & 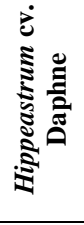 & 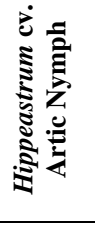 & 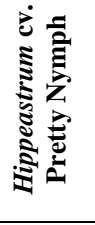 & 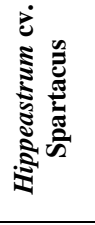 & $\begin{array}{c}\text { Ref. } \\
\text { for } \\
\text { MS, RI data }\end{array}$ \\
\hline Ismine & 2278 & 2280 & $\mathrm{t}$ & & & $\mathrm{t}$ & & & [7] \\
\hline Trisphaeridine & 2284 & 2282 & $\mathrm{t}$ & & & & & & {$[8]$} \\
\hline Galanthamine & 2408 & 2410 & & & $\mathrm{t}$ & $\mathrm{t}$ & & $\mathrm{t}$ & $\mathrm{c}, \mathrm{d},[9]$ \\
\hline Lycoramine & 2442 & 2417 & & $<1$ & $\mathrm{t}$ & & & & $\mathrm{c}, \mathrm{d}[10]$ \\
\hline Vittatine/crinine* & 2498 & 2472 & 9 & 9 & $<1$ & 4 & & 3 & $\mathrm{c}, \mathrm{d},[7]$ \\
\hline A1 & 2518 & n.a. & & & 3 & & & & \\
\hline 9- $O$-Demethyllycosinine B & 2575 & 2499 & $\mathrm{t}$ & $<1$ & & & & & [11] \\
\hline 11,12-Dehydroanhydrolycorine & 2604 & 2606 & $<1$ & & $\mathrm{t}$ & & & & {$[7,9]$} \\
\hline A2 Homolycorine type & 2609 & n.a. & & 3 & $<1$ & & & & \\
\hline Montanine & 2615 & 2611 & 6 & 16 & & & 21 & 12 & $\mathrm{c}, \mathrm{d},[7]$ \\
\hline Haemanthamine & 2640 & 2641 & 3 & 4 & 3 & 4 & & 8 & $\mathrm{c}, \mathrm{d},[7]$ \\
\hline Tazettine/Pretazzenine* & 2655 & 2653 & 5 & & $\mathrm{t}$ & & & 43 & $\mathrm{c}, \mathrm{d},[7]$ \\
\hline Pancracine & 2719 & 2718 & 7 & 6 & & & 3 & & $\mathrm{c}, \mathrm{d},[7]$ \\
\hline 11-Hydroxyvittattine & 2736 & 2732 & 49 & 23 & & 18 & & 8 & $\mathrm{c},[9]$ \\
\hline Lycorine & 2749 & 2746 & 9 & 30 & 56 & 44 & 15 & 26 & $\mathrm{c}, \mathrm{d},[7]$ \\
\hline Homolycorine & 2769 & 2767 & 5 & 2 & & & 40 & & $\mathrm{c},[8]$ \\
\hline 3-Epimacronine & 2813 & 2811 & $\mathrm{t}$ & & & & & & $\mathrm{c}, \mathrm{d},[7]$ \\
\hline Pseudolycorine & 2823 & 2831 & 4 & 2 & 3 & 15 & & & {$[9,10]$} \\
\hline Hippeastrine & 2918 & 2917 & 1 & 3 & 34 & 5 & 22 & $\mathrm{t}$ & $\mathrm{c},[7]$ \\
\hline A3 & 3012 & n.a. & & & & 4 & $\mathrm{t}$ & & \\
\hline
\end{tabular}

To study the anticancer effect of three of the isolated compounds, which have not been described by our laboratory previously \{montanine (1), vittatine (2) and hippeastrine (5)\}, cytotoxic and antiproliferative potencies were screened on a panel of human cancer cells of different histotype (Jurkat, MOLT-4, A549, HT-29, PANC-1, A2780, HeLa, MCF-7 and SAOS-2). In parallel, normal MRC-5 human fibroblasts were employed to determine the compounds' overall toxicity against non-cancer cells. The cytotoxic activity of these alkaloids was evaluated using the WST-1 metabolic activity assay. To find the best of them with very high cytotoxicity, the alkaloids were tested for growth-inhibitory activity in all 10 cell lines at a single dose of $10 \mu \mathrm{M}$ (Figure 2). For each alkaloid tested, the sensitivity in an individual cell line and the mean growth percent (GP) value was calculated as an average of 10 cell lines proliferation in percent (Table S1). The threshold GP value for this screen was < 50\% (50\% tumor growth inhibition), indicating good activity at $10 \mu \mathrm{M}$. The most active alkaloid in the field of cytotoxicity and antiproliferative activity seemed to be montanine (1), which was found to inhibit Jurkat, MOLT-4, A549, HT-29, PANC-1, A2780, HeLa, MCF-7 and SAOS-2 cancer cell growth with a score $\leq 50 \%$ at $10 \mu \mathrm{M}$ 
concentration (Table $\mathrm{S} 2$ ). Thus, $\mathrm{IC}_{50}$ values of montanine (1) in the range below $10 \mu \mathrm{M}$ were determined. As shown in Table 2, montanine (1) showed highest activity towards Jurkat, MOLT-4 and A549 cells. Jurkat cells were highly sensitive to montanine treatment (1), with an $\mathrm{IC}_{50}$ of $1.04 \mu \mathrm{M}$.

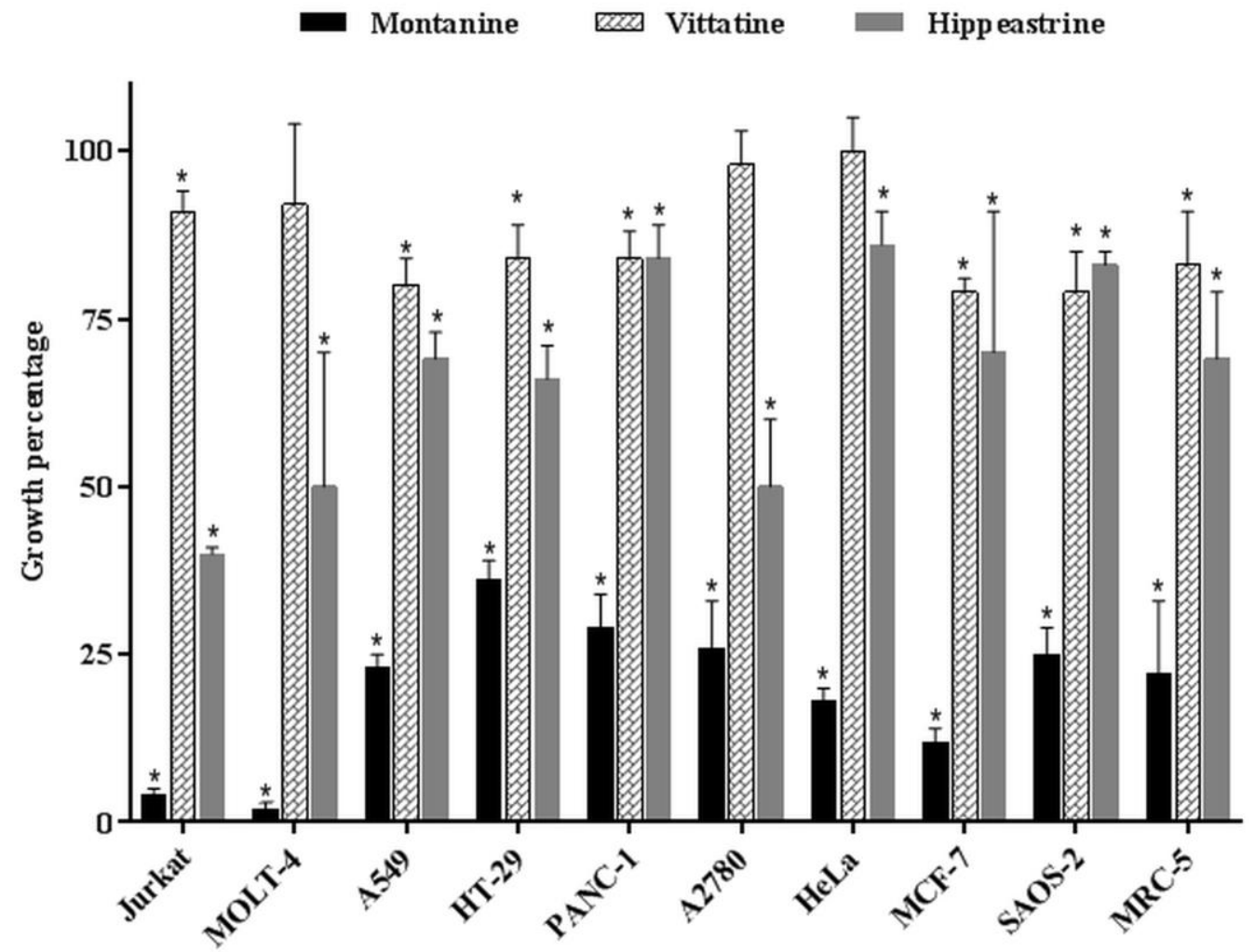

Figure 2. The growth inhibitory effect of montanine, vittatine and hippeastrine following a single-dose exposure at a concentration of $10 \mu \mathrm{M}$ on 9 cancer cell lines (Jurkat, MOLT-4, A549, HT-29, PANC-1, A2780, HeLa, MCF-7, SAOS-2) and the non-cancer cell line MRC-5 using WST-1 cytotoxicity assay. Bars indicate mean $\pm \mathrm{SD}, \mathrm{n}=3 . *$ - significantly different from $0.1 \%$ DMSO mock treated control $(\mathrm{p} \leq 0.05)$.

Alkaloids of montanine structural type such as montanine (1), pancracine (7), coccinine (8) and manthine (6) seem to be promising compounds in the search for new anticancer drugs. They are characterized by a 5,11-methanomorphantridine ring system and differ only in the substitutions and configuration at C-2 and C-3 centers (Figure 1) [12]. Some of these compounds have been screened on different cancerous cells [13,14]. Montanine (1) and manthine (6) showed strong in vitro growth inhibitory effect on three cancer cell lines resistant to apoptosis (A549, SKMEL-29, U373) and three cancer cell lines sensitive to apoptosis (MCF7, Hs683, B16F10) with $\mathrm{IC}_{50}$ values between 5 and $31 \mu \mathrm{M}$ [14], but for both of them the molecular mechanism of the anticancer activity is still waiting to be described. In another recent study, the C-2 $\alpha-/ C-2 \beta$-methoxy isomers montanine (1) and coccinine (8) were found to have a significant effect on the proliferation of human breast, colon, lung, and melanoma cancer cell lines during $48 \mathrm{~h}$ of treatment. The obtained results revealed that montanine (1) has a more promising cytotoxic activity $\left(\mathrm{IC}_{50}\right.$ values were $1.9 \pm 0.4 \mu \mathrm{M}$ for $\mathrm{A} 549$ cells, $6.8 \pm 0.5 \mu \mathrm{M}$ for HCT-15 cells, $23.2 \pm 1.9 \mu \mathrm{M}$ for SK-MEL-28 cells, $4.4 \pm 0.4 \mu \mathrm{M}$ for MCF-7 cells, $3.4 \pm 0.9 \mu \mathrm{M}$ for MDA-MB231 cells, $3.6 \pm 1.7 \mu \mathrm{M}$ for Hs578T cells) in comparison with coccinine (8) ( IC $_{50}$ values were $5.9 \pm 0.8$ $\mu \mathrm{M}$ for A549 cells, $16.8 \pm 1.8 \mu \mathrm{M}$ for HCT-15 cells, $>50 \mu \mathrm{M}$ for SK-MEL-28 cells, $7.9 \pm 0.9 \mu \mathrm{M}$ for MCF-7 cells, $13.8 \pm 0.8 \mu \mathrm{M}$ for MDA-MB-231 cells, $5.3 \pm 0.4 \mu \mathrm{M}$ for Hs578T cells) [15]. However, since previous studies demonstrated that montanine (1), manthine (6) and coccinine (8) could effectively suppress viability and proliferation of human cancer cells, the molecular mechanism of their cytotoxic activity has not yet been fully explored and is still waiting to be described. 
Table 2. $\mathrm{IC}_{50}$ values of montanine (1) for

\begin{tabular}{|c|c|}
\hline Cell type & $\operatorname{IC}_{50}(\mu \mathrm{M})^{\mathrm{a}, \mathrm{b}}$ \\
\hline Jurkat & $1.04 \pm 0.14$ \\
\hline MOLT-4 & $1.26 \pm 0.11$ \\
\hline A549 & $1.09 \pm 0.31$ \\
\hline HT-29 & $1.35 \pm 0.47$ \\
\hline PANC-1 & $2.30 \pm 0.45$ \\
\hline A2780 & $1.67 \pm 0.29$ \\
\hline HeLa & $1.99 \pm 0.22$ \\
\hline MCF-7 & $1.39 \pm 0.21$ \\
\hline SAOS-2 & $1.36 \pm 0.49$ \\
\hline MRC-5 & $1.79 \pm 0.50$ \\
\hline
\end{tabular}

In conclusion, plants of the genus Hippeastrum are an interesting source of Amaryllidaceae alkaloids of different structural types. The Hippeastrum cultivar Pretty Nymph has been selected for detailed phytochemical study because of its high content of the alkaloid montanine (16\% of TIC), which showed promising cytotoxic activity on a panel of nine cancerous cell lines. After isolation of a sufficient amount of montanine from $H$. cv Pretty Nymph, the molecular mechanism of the compound's cytotoxic activity will be studied in more detail. To look at montanine's ability to decrease the proliferation of cancer cells, the real-time label free cell proliferation method xCELLigence RTCA will be used. The impact of montanine on the distribution of cell population in a specific phase of cell cycle and induction of apoptosis will be determined using a flow-cytometry method. If either the intrinsic or extrinsic pathway of apoptosis is involved in montanine-induced cytotoxicity, activity of caspases, especially of $3 / 7,-8$, and 9 will be measured. The follow-up step to reveal the molecular mechanism underlying the cytotoxic effect of montanine will be the detection of proteins related to apoptosis induction or to activation of cell cycle check point controls.

\section{Acknowledgments}

The authors wish to thank Prof. Gerald Blunden for critical reading of the manuscript and corrections of English. This project has been supported by Charles University grants (GA UK Nr. 178518, SVV UK 260 412; 260 401; Progres/UK Q40 and Q42), and by the Pre-application research into innovative medicines and medical technologies project (Reg. No. CZ.02.1.01/0.0/0.0/18_069/0010046) co-funded by the European Union.

\section{Supporting Information}

Supporting information accompanies this paper on http://www.acgpubs.org/journal/records-ofnatural-products

\section{ORCID}

Latifah Al Shammari: 0000-0002-9835-0695

Abdullah Al Mamun: 0000-0002-3441-8814

Darja Koutová: 0000-0002-7311-4119

Martina Majorošová: 0000-0002-3595-2568

Daniela Hulcová: 0000-0003-2414-3551

Marcela Šafratová: 0000-0003-4690-5107

Kateřina Breiterová: 0000-0003-4784-5601

Jana Mař́ková: 0000-0001-9758-2067

Radim Havelek: 0000-0003-0528-1334 
Lucie Cahlíková: $\underline{\text { 0000-0002-1555-8870 }}$

\section{References}

[1] K. Carter (2007). Amaryllis: Amaryllis belladonna (Brunsvigia rosea) and Hippeastrum hybrids. Center for Landscape and Urban Horticulture, Cooperative Extension/Botany Plant Sciences Department. University of California Riverside.

[2] C.P. Deepa and B.B. Kuriakose (2014). Pharmacognostic and phytochemical evaluation of the bulbs of Hippeastrum puniceum (Lam.) Voss, Int. J. Pharmacog. Phytochem. Res. 6, 399-404.

[3] K. Habartová, L. Cahlíková, M. Řezáčová and R. Havelek (2016). The biological activity of alkaloids from the Amaryllidaceae: from cholinesterases inhibition to anticancer activity, Nat. Prod. Commun. 11, 15871594.

[4] R. Havelek, D. Muthná, P. Tomšík, K. Královec, M. Seifrtová, L. Cahlíková, A. Hošt’álková, M. Šafratová, M. Perwein, E. Čermáková and M. Řezáčová (2017). Anticancer potential of Amaryllidaceae alkaloids evaluated by screening with a panel of human cells, real-time cellular analysis and Ehrlich tumor-bearing mice, Chem. Biol. Int. 275, 121-132.

[5] I. Doskočil, A. Hoštálková, M. Šafratová, N. Benešová, J. Havlík, R. Havelek, J. Kuneš, K. Královec, J. Chlebek and L. Cahlíková (2015). Cytotoxic activities of Amaryllidaceae alkaloids against gastrointestinal cancer cells. Phytochem. Lett. 13, 394-398.

[6] H.K. Schnoes, D.T. Smith, A.L. Burlingame, P.W. Jeffs and W. Döpke (1968). Mass spectra of Amaryllidaceae alkaloids: The lycorenine series, Tetrahedron 24, 2825-2837.

[7] J.P. de Andrade, R.B. Giordani, L. Torras-Claveria, N.B. Pigni, S. Berkov, M. Font-Bardia, T. Calvet, E. Konrath, K. Bueno, L.G. Sachett, J.H. Dutilh, W. de Souza Borges, F. Viladomat, A.T. Henriques, J.J. Nair, J.A.S. Zuanazzi and J. Bastida (2016). The Brazilian Amaryllidaceae as a source of acetylcholinesterase inhibitory alkaloids, Phytochem. Rev. 15, 147-160.

[8] S. Berkov, J. Bastida, B. Sidjimova, F. Viladomat and C. Codina (2008). Phytochemical differentiation of Galanthus nivalis and Galanthus elwesii (Amaryllidaceae): A case study, Biochem. System. Ecol. 36, 638645.

[9] R.L. Tallini, J. Bastida, N. Cortes, H.E. Osorio, C. Theoduloz and G. Schmeda-Hirschmann (2019). Cholinesterase inhibition activity, alkaloid profiling and molecular docking of Chilean Rhodophiala (Amaryllidaceae), Molecules 23, 1532/1-1532/27.

[10] L.M Trujillo-Chacón, J. E. Alarcón-Enos, C. L. Céspedes-Acuna, L.Bustamante, M. Baeza, M. G. López, C. Fernández-Mendívil, F. Cabezas and E. R. Pastene-Navarete (2019). Neuroprotective activity of isoquinoline alkaloids from Chilean Amaryllidaceae against oxidative stress-induced toxicity on human neuroblastoma SH-SY5Y cells and mouse hippocampal slice culture, Food Chem. Toxicol. 132, 11065.

[11] Y. Guo, J.P. de Andrade, NB. Pigni, L. Torras-Claveria, L. R. Tallini, W. de S. Borges, F. Viladomat, J.J. Nair, J.A.S. Zuanazzi and J. Bastida (2016). New alkaloids from Hippeastrum papilo (RAVENNA) VAN SCHEEPEN, Helv. Chim. Acta 99, 143-147.

[12] X. Bao, Y.-X. Cao, W.-D. Chu, H. Qu, J.-Y. Du, X.-H. Zhao, X.-Y. Ma, C.-T. Wang and C.-A. Fan (2013). Bioinspired total synthesis of montanine-type Amaryllidaceae alkaloids, Angew. Chem. 52, 14167-14172.

[13] M. Farinon, V.S. Clarimundo, G.P. Pedrazza, P.S. Gulko, J.A. Zuanazzi, R.M. Xavier and P.G. de Oliveira (2017). Disease modifying anti-rheumetic activity of the alkaloid montanine on experimental arthritis and fibroblast-like synoviocytes, Eur. J. Pharmacol. 15, 180-187.

[14] K. Govindaraju, A. Ingels, M.N. Hasan, D. Sun, V. Mathieu, V. Masi, A. Evidente and A. Kornienko (2018). Synthetic analogues of the montanine-type alkaloids with activity against apoptosis-resistant cancer cells, Bioorg. Med. Chem. Lett. 28, 589-593.

[15] M. Masi, S. van Slambrouck, S. Gunawardana, M.J. van Rensburg, P.C. James, J.G. Mochel, P.S. Heliso, A.S. Albalawi, A. Cimmino, W.A.L. van Otterlo, A. Kornienko, I.R. Green and A. Evidente (2019) Alkaloids isolated from Haemanthus humilis Jacq., an indigenous South African Amaryllidaceae: Anticancer activity of coccinine and montanine, S. Afr. J. Bot., (https://doi.org/10.1016/j.sajb.2019.01.036).

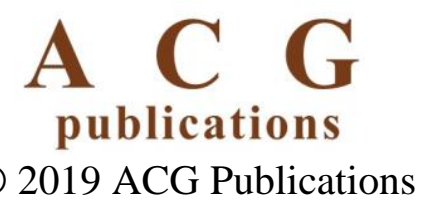

